\title{
Antipsychotics for patients with pain
}

Departments of ${ }^{1}$ Anesthesia and Pain Medicine, ${ }^{2}$ Psychiatry, Pusan National University, Busan, Korea, ${ }^{3}$ Department of Pain Medicine, Division of Anesthesia and Critical Care, The University of Texas MD Anderson Cancer Center, Houston, TX, USA

\section{Sang Wook Shin', Jin Seong Lee ${ }^{2}$, Salahadin Abdi ${ }^{3}$, Su Jung Lee', and Kyung Hoon Kim}

Going back to basics prior to mentioning the use of antipsychotics in patients with pain, the International Association for the Study of Pain (IASP) definition of pain can be summarized as an unpleasant experience, composed of sensory experience caused by actual tissue damage and/or emotional experience caused by potential tissue damage. Less used than antidepressants, antipsychotics have also been used for treating this unpleasant experience as adjuvant analgesics without sufficient evidence from research. Because recently developed atypical antipsychotics reduce the adverse reactions of extrapyramidal symptoms, such as acute dystonia, pseudo-parkinsonism, akathisia, and tardive dyskinesia caused by typical antipsychotics, they are expected to be used more frequently in various painful conditions, while increasing the risk of metabolic syndromes (weight gain, diabetes, and dyslipidemia). Various antipsychotics have different neurotransmitter receptor affinities for dopamine (D), 5-hydroxytryptamine (5-HT), adrenergic ( $\alpha$ ), histamine (H), and muscarinic (M) receptors. Atypical antipsychotics antagonize transient, weak $\mathrm{D}_{2}$ receptor bindings with strong binding to the $5-\mathrm{HT}_{2 \mathrm{~A}}$ receptor, while typical antipsychotics block long-lasting, tight $\mathrm{D}_{2}$ receptor binding. On the contrary, antidepressants in the field of pain management also block the reuptake of similar receptors, mainly on the 5-HT and, next, on the norepinephrine, but rarely on the D receptors. Antipsychotics have been used for treating positive symptoms, such as delusion, hallucination, disorganized thought and behavior, perception disturbance, and inappropriate emotion, rather than the negative, cognitive, and affective symptoms of psychosis. Therefore, an antipsychotic may be prescribed in pain patients with positive symptoms of psychosis during or after controlling all sensory components. (Korean J Pain 2019; 32: 3-11)

Key Words: Antipsychotics; Dopamine; Drug related side effects and adverse reactions; $\mathrm{D}_{2}$ receptor antagonists; Extrapyramidal symptom; Histamine; Pain; Prolactin; Psychosis; Serotonin; Weight gain.

\section{INTRODUCTION}

The International Association for the Study of Pain (IASP) definition of pain can be summarized as an unpleasant $\mathrm{ex}^{-}$ perience, composed of sensory experience caused by actual tissue damage and/or emotional experience caused by potential tissue damage [1]. During and after treating all sensory components including nociceptive and neuropathic pain, patients may complain of mysterious or vague generalized pain which are supposed to originate from the component of emotional experience.

Pain physicians are accustomed to use antidepressants

Received September 18, 2018. Revised December 5, 2018. Accepted December 6, 2018.

Correspondence to: Kyung Hoon Kim

Pain Clinic, Pusan National University Yangsan Hospital, 20 Geumo-ro, Mulgeum-eup, Yangsan 50612, Korea

Tel: +82-55-360-1422, Fax: +82-55-360-2149, E-mail: pain@pusan.ackr

(a) This is an open-access article distributed under the terms of the Creative Commons Attribution Non-Commercial License (http:// creativecommons.org/licenses/by-nc/4.0/), which permits unrestricted non-commercial use, distribution, and reproduction in any medium, provided the original work is properly cited.

Copyright (c) The Korean Pain Society, 2019 
for treating not only negative neuropathic pain symptoms, such as hypoesthesia/anesthesia and weakness, but also depressive mood. Anxiolytics, which reduce anxiety, and produce sedation and sleep from the lower to higher dose, are also familiar to them. However, they hesitate to use antipsychotics due to their major adverse reactions (ADRs) such as extrapyramidal symptoms (EPSs), even though the mechanisms of action, mainly acting on serotonin, norepinephrine, and dopamine, are quite similar.

Psychiatric symptoms and disorders include delirium, schizophrenia, delusional disorder, mood disorder, dementia, substance abuse, metabolic disturbances, chronic medical conditions, or drug-induced psychosis [2,3].

Antipsychotics are medications which are primarily used to manage schizophrenia and bipolar disorder. Antipsychotics have been prescribed for treating the 4 major symptoms of schizophrenia: positive (delusion, hallucination, disorganized thought and behavior, perception disturbance, and inappropriate emotion), negative (flat affect, poverty of thought, amotivation, and social withdrawal), cognitive (distractibility, impaired working memory, and impaired executive function), and affective (mania and depression) symptoms. However, antipsychotics are more effective on positive symptoms than negative symptoms. Mood symptoms are better controlled by antidepressants, and no drug treatment has been proven effective in cognitive deficits [2-4].

Typical antipsychotics have been tried in many intractable and unresponsive pain states as analgesics or adjuvants, however, adverse reactions (ADRs), such as extrapyramidal symptoms (EPSs) and sedation, would follow $[5,6]$. Chlorpromazine and haloperidol are representative typical antipsychotics. Chlorpromazine is one of the phenothiazine derivatives, and was originally developed during the development of the lytic cocktail for the prevention of surgical shock. As it showed decreased motor activity and affective indifference, it was used as an antipsychotic [7]. Haloperidol was a byproduct of meperidine during the search for a more powerful analgesic. It was found to have the effect of reducing an emotional crisis to the state of sedation. It is also effective to decrease emesis after an operation or opioid prescription [7].

One of the problems in prescribing conventional typical antipsychotics is that they can produce many ADRs. Depending on their actions with dopaminergic, adrenergic, cholinergic, serotonergic, and histaminergic receptors, they can present various ADRs. The representative ADRs of typical antipsychotics are EPSs, such as acute dystonia, pseudo-parkinsonism, akathisia, and tardive dyskinesia. Other ADRs are anticholinergic effects, orthostatic hypotension, seizure, and prolactin elevation. The ADRs, including EPSs caused by typical antipsychotics, had spurred the development of atypical antipsychotics, starting with clozapine in 1958 [7]. Recently developed atypical antipsychotics decrease the above ADRs, but still they increase the potential risk of metabolic syndromes (weight gain, diabetes, and dyslipidemia).

This article provides the classification, action mechanisms, clinical application (favorable symptoms), their equivalent doses, and ADRs of antipsychotics and their treatment of antipsychotics.

\section{MAIN BODY}

\section{Classification of antipsychotics}

Antipsychotics can be classified as old, conventional, typical, or first generation antipsychotics (FGAs), and modern, novel, atypical or second generation antipsychotics (SGAs) (Table 1). They are classified according to their development and release, as well as their actions and ADRs.

Table 1. Typical and Atypical Antipsychotics

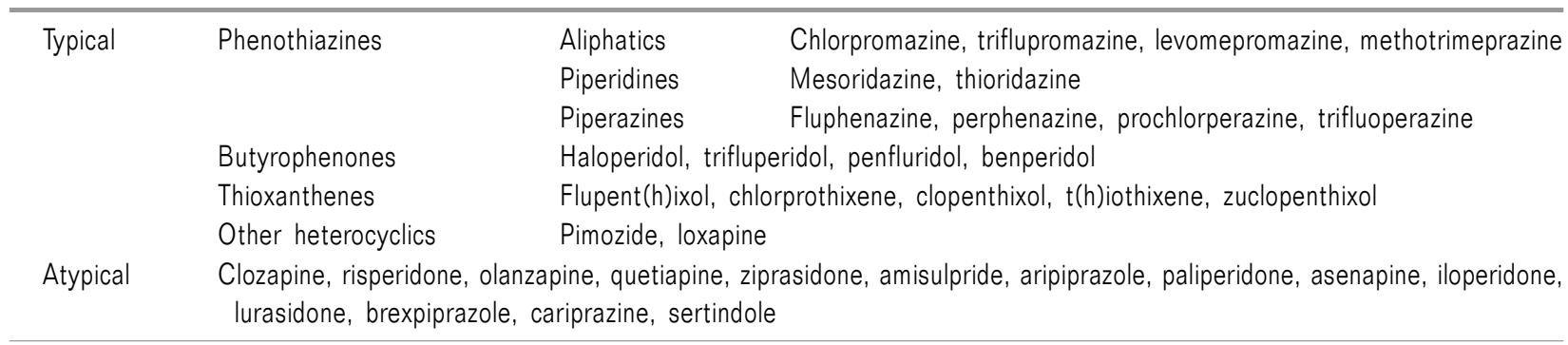




\section{1) Typical antipsychotics}

Typical antipsychotics, FGAs, can be chemically classified as phenothiazine, butyrophenone, thioxanthene, and other heterocyclics.

Chlorpromazine from the phenothiazine class, was synthesized and used clinically in 1952, as the first classical antipsychotic [7].

Haloperidol, in the butyrophenone class, was synthesized during the development of analgesics from meperidine (1958).

Then, trifluoperazine $\left(\right.$ Eskazynil $^{\circledR}$, Stelazine ${ }^{\circledR}$, 1959), thioridazine (Mellaril $^{\circledR}$, Melleril ${ }^{\circledR}$, 1959 till withdrawal in 2005 due to cardiac arrhythmia), and fluphenazine (Prolixin ${ }^{\circledR}$, Modecate ${ }^{\circledR}$, Moditen ${ }^{\circledR}$, 1959), a class of phenothiazines, came into use successively $[7,8]$.

Flupent(h)ixol (Depixol ${ }^{\circledR}$, Fluanxol ${ }^{\mathbb{R}}$ ) from the thioxanthene class, was introduced in 1965 [9].

\section{2) Atypical antipsychotics}

At least 17 atypical antipsychotics, SGAs, have been introduced and some drugs have already been withdrawn because of ADRs. Clozapine (Clozaril ${ }^{\mathbb{R}}$ ) is the prototypic atypical antipsychotic drug. It was synthesized in 1958 and tried clinically. But it turned out to be effective, with fewer neurologic ADRs for psychosis in 1966. It was launched in Europe, then introduced in the United States in 1989.

'Atypical' means these kinds of drugs don't produce EPSs that all the conventional antipsychotics possessed. Therefore, these new modern antipsychotics were described as 'atypical' [7].

That atypical drug development was followed by the introduction to the market of risperidone (Resperdal ${ }^{\mathbb{R}}$, 1994), olanzapine (Zyprexa $\left.{ }^{\circledR}, 1996\right)$, quetiapine (Seroquel ${ }^{\circledR}$, 1998), ziprasidone (Geodon $\left.{ }^{\circledR}, 2001\right)$, amisulpride (Solian ${ }^{\circledR}$, 2002), aripiprazole (Abilify $\left.{ }^{\circledR}, 2002\right)$, paliperidone (Invega ${ }^{\circledR}$, 2006), asenapine (Saphris ${ }^{\circledR}$, Sycrest ${ }^{\circledR}$, 2009), iloperidone (Fanapt $^{\circledR}$, Fanapta ${ }^{\circledR}$, 2009), lurasidone (Latuda ${ }^{\circledR}$, 2010), sertindole (Serdolect ${ }^{\circledR}$, Serlect $\left.{ }^{\circledR}, 2013\right)$, brexpiprazole (Rexulti $\left.{ }^{\circledR}, 2015\right)$, and cariprazine (Vraylar ${ }^{\circledR}$, Reagila ${ }^{\circledR}, 2015$ ) [8].
2. Mechanism of action, clinical application, and adverse reactions

\section{1) Typical antipsychotics}

\section{(1) Mechanism of action}

Antipsychotics have different receptor affinities for many neurotransmitters. It is many decades since chlorpromazine and haloperidol, the classic FGAs, were introduced and used clinically, and it is well established that their effects are via their action on dopamine receptors. By the increased level of monoamines, the classic FGAs were thought to act through increasing the turnover of monoamines and blocking monoamine receptors [10].

It is essential to understand the relevance of the classic concept of psychosis with 4 dopamine pathways: (a) mesolimbic pathways, related to positive symptoms (reward and pleasure), from the ventral tegmental area (VTA) located close to the midline on the floor of the midbrain, to the limbic system (including the amygdala and hippocampus), (b mesocortical pathways, associated with negative, cognitive, and affective symptoms (motivation and emotions), from the VTA to the cortex, (c) nigrostriatal pathways, related to voluntary movement resulting in EPSs, from the substantia nigra pars compacta (the basal ganglia structure located in the midbrain, that plays an important role in reward and movement) to the dorsal striatum (the caudate nucleus and putamen, involved in the production of movement), (d) tuberoinfundibular pathways, related to hyperprolactinemia, from the infundibular nucleus (arcuate nucleus) in the tuberal region of the hypothalamus to the median eminence of the hypothalamus that regulates secretion of prolactin from the anterior $\mathrm{pi}^{-}$ tuitary gland $[11,12]$.

\section{(2) Clinical applications, adverse reactions, and treat- ments of adverse reactions}

Making a connection with the 4 dopaminergic pathways relevant to the FGAs, the mechanisms of their action are antagonism to the $\mathrm{D}_{2}$ receptor in the brain, including (a) blockade of the mesolimbic pathway hyperactivation, related to the positive symptoms of psychosis, (b) hypofunction or dysfunction of the mesocortical pathway, related to negative, affective, and cognitive symptoms, (c) 
blockade of the nigrostriatal pathway, associated with increased risk of EPSs, and (d) blockade of the tuberoinfundibular pathway, engaged in increased prolactin levels in the pituitary gland. Therefore, the blockade of the mesolimbic and mesocortical pathways is deeply related to the therapeutic effects of the FGAs, however, blockade of the nigrostriatal and tuberoinfundibular pathways are used to explain the ADRs of FGAs (Table 2) [11,12].

Matching the action mechanisms of FGAs up with EPSs, the representative ADRs, are explained by the blockade of the $D_{2}$ receptors in the nigrostriatal pathway. It is also very important to recognize EPSs in an early phase for the patients taking FGAs. The drug-induced extrapyramidal symptoms scale (DIEPSS) is composed of 8 symptoms as well as the overall severity with their 5 level grading system [0 (normal), 1 (minimal), 2 (mild), 3 (moderate), and 4 (severe)]: (1) gait, (2) bradykinesia, (3) sialorrhea, (4) muscle rigidity, (5) tremors, (6) akathisia, (7) dystonia, (8) dyskinesia, and (9) overall severity [13-15].

The representative EPSs are acute dystonia, pseudo-parkinsonism, akathisia, and tardive dyskinesia (Table 2). The pyramidal tract transmits motor signals through the anterior and lateral corticospinal or corticobulbar tract directly. However, the extrapyramidal system modulates or regulates motor signals (involuntary movement with reflexes, locomotion, complex movements, and postural con- trol) indirectly, without prominent innervating motor neurons (they are supposed to transmit through the rubrospinal, reticulospinal, olivospinal, or vestibulospinal tract related to the nigrostriatal pathway, basal ganglia of the subcortical and midbrain structures, cerebellum, and sensory area of the cerebral cortex) [16].

Dystonia is a movement disorder characterized by sustained or intermittent muscle contractions, causing abnormal posture, and/or repetitive movements $[17,18]$. The common FGA-induced acute dystonia includes facial grimacing, involuntary upward eye movement, muscle spasms of the tongue, face, neck, and back, as well as laryngeal spasms. Acute dystonia is the earliest EPS, starting from a few hours to 5 days after administration. It usually reverses from a few hours to 1-2 days after discontinuation. It occurs in less than $10 \%$ of cases, but may develop in up to $40 \%$ in young male patients [16]. FGA-induced acute dystonia, although self-limiting, can be treated with antihistamines (such as diphenhydramine) or anticholinergics [1-6 mg of benz(a)tropine] initially, and benzodiazepines later, in cases of ineffectiveness.

Pseudo-parkinsonism, observed weeks to months after administration of FGAs, presents similar symptoms and signs to Parkinson's disease, as a neurodegenerative disease. However, differences between parkinsonism and pseudo-parkinsonism may lie in bradykinesia versus apraxic

Table 2. Mechanism of Action, Clinical Application, and Adverse Reactions and Their Treatments of Typical Antipsychotics Related to Blockade of 4 Dopaminergic Pathways

\begin{tabular}{|c|c|c|}
\hline $\begin{array}{l}\text { Blockade of the } \\
\text { dopaminergic pathways }\end{array}$ & $\begin{array}{c}\text { Related target symptoms of } \\
\text { psychosis using typical } \\
\text { antipsychotics }\end{array}$ & Detail target symptoms \\
\hline Mesolimbic pathway & Positive symptoms & $\begin{array}{l}\text { Delusion, hallucination, disorganized thought and behavior, perception } \\
\text { disturbance, and inappropriate emotion }\end{array}$ \\
\hline \multirow[t]{3}{*}{ Mesocortical pathway } & Negative symptoms & Flat affect, poverty of thought, amotivation, and social withdrawal \\
\hline & Cognitive symptoms & $\begin{array}{l}\text { Distractibility, impaired working memory, and impaired executive } \\
\text { function }\end{array}$ \\
\hline & Affective symptoms & Mania and depression \\
\hline $\begin{array}{l}\text { Blockade of the } \\
\text { dopaminergic pathways }\end{array}$ & $\begin{array}{l}\text { Adverse reactions provoked } \\
\text { by typical antipsychotics }\end{array}$ & Detail adverse symptoms and their treatments \\
\hline Nigrostriatal pathway & Extrapyramidal symptoms & $\begin{array}{l}\text { Dystonia: antihistamine (diphenhydramine) or anticholinergics [1-6 mg } \\
\text { of benz(a)tropine] at first and benzodiazepines later } \\
\text { Pseudo-parkinsonism: anticholinergics or ( } 100-40 \mathrm{mg} \text { of) amantadine } \\
\text { Akathisia: beta-clockers (30-120 mg of propranolol), anticholinergics, or } \\
\text { benzodiazepines } \\
\text { Tardive dvskinesia: valbenazine }(125-100 \mathrm{ma} / \mathrm{d}) \text { for } 6 \text { weeks }\end{array}$ \\
\hline Tuberoinfundibular pathway & Hyperprolactinemia & \\
\hline
\end{tabular}


slowness, resting tremors versus essential tremors/myoclonus, lead pipe rigidity versus paratonic rigidity, postural instability versus frontal ataxia, and slow, shuffling gait with festination and retropulsion versus slow, shuffling apraxic gait, respectively [19]. Treatment includes anticholinergics or (100-400 mg/d of) amantadine, lowering the dose of antipsychotics, and changing to SGAs.

Akathisia refers to a subjective feeling of restlessness with anxiety and objective repetitive or restless motor activity days to weeks after administration. It is believed to develop due to a blockade of the mesocortical pathways and increased norepinephrine in the limbic region. Treatment includes beta-blockers (30-120 mg of propranolol), anticholinergics, benzodiazepines, lowering the dose of antipsychotics, and changing to SGAs [18].

Tardive dyskinesia refers to involuntary, repetitive hyperkinetic movements, including grimacing, sticking out the tongue, or smacking of the lips resulting from long-term use (-5 years: $31.8 \%,-10$ years: $49.4 \%,-15$ years: $56.7 \%$, -20 years: $64.7 \%$, 25- years: $68.4 \%$ ) of FGAs or aripiprazole (SGA) because of supersensitivity in the nigrostriatal pathway [20].

The abnormal involuntary movement scale (AIMS) is the most popular method for evaluating drug-induced tardive dyskinesia. It is composed of 14 items from evaluating 5 different body areas, including (1) orofacial movements (muscles of facial expression/lips and perioral area/jaw/ tongue, 0 = none, 1 = minimal, 2 = mild, 3 = moderate, 4 = severe), (2) extremity movements (upper extremities/ lower extremities, from 0 to 4), (3) trunk movements (neck, shoulders, and hips, from 0 to 4), (4) global judgements (overall severity of abnormal movements/incapacitation due to abnormal movements/patient's awareness of abnormal movements, from 0 to 4), (5) dental status (current problems with teeth and/or dentures/worn dentures/edentia/do movements disappear with sleep?, 0 = no or 1 = yes) [21].

Valbenazine $(12.5-100 \mathrm{mg} / \mathrm{d})$ for 6 weeks is the first FDA-approved treatment for tardive dyskinesia. It causes a reversible reduction of dopamine release by selectively inhibiting presynaptic human vesicular monoamine transporter type 2 (VMAT2) [22].

Core features of delirium are disturbance of consciousness, change in cognition, evidence from the history, physical examination, or laboratory findings that the signs and symptoms are the direct physiological consequences of a medical condition or substance use. The other common features include hallucination, delusions, or inappropriate affective states. Haloperidol is the most frequent drugs with a dose of 0.25 to $0.5 \mathrm{mg}$ every 4 hours for the elderly and $3 \mathrm{mg}$ once per day in healthy patients. In addition, 4.5 to $5.1 \mathrm{mg}$ per day of olanzapine and 25-200 mg of quetiapine, which are atypical antipsychotics, have an enough evidence for the treatment of delirium while preventing EPSs from haloperidol [23].

FGAs also work as the acetylcholine muscarinic Ml antagonists, histamine $\mathrm{Hl}$ antagonists, and $\alpha_{1}$ adrenergic antagonists. All these actions on neurotransmitter receptors will evoke ADRs after treatment (Table 3, 4) [24,25]. FGAs for these receptors present ADRs like dry mouth, constipation, sleepiness, weight gain, and orthostatic hypotension, which are similar to those of typical antidepressants.

\section{2) Atypical antipsychotics}

\section{(1) Mechanism of action}

SGAs have fewer ADRs, such as EPSs, which distinguishes them from FGAs [2-4]. The SGAs also work on multiple neurotransmitter receptors, including not only the dopamine receptors, but also the serotonin (5-HT), histamine, adrenalin, and muscarinic acetylcholine receptors. Their affinity to each receptor is different, and the disparity among receptor affinity could explain the mechanism of action and adverse reactions of each drug (Table 3, 4) [24,25].

The representative characteristic mechanisms of ac-

Table 3. Adverse Reactions by Receptor Blockade of Antipsychotics

\begin{tabular}{|c|c|}
\hline Receptors & Adverse reactions \\
\hline$D_{2}$ & EPSs, prolactin elevation \\
\hline$M_{1}$ & $\begin{array}{l}\text { Cognitive deficits, Gl symptoms, dry mouth, } \\
\text { constipation, increased heart rate, urinary retention, } \\
\text { blurred vision, reduced EPSs }\end{array}$ \\
\hline $\mathrm{H}_{1}$ & Sedation, weight gain, dizziness \\
\hline$\alpha_{1}$ & Hypotension, sedation, weight gain \\
\hline $5 \mathrm{HT}_{2 \mathrm{~A}}$ & Anti- EPSs (?) \\
\hline $5 \mathrm{HT}_{2} \mathrm{C}$ & Satiety blockade \\
\hline
\end{tabular}

D: dopamine, EPSs: extrapyramidal symptoms, Gl: gastrointestinal, $\mathrm{M}$ : muscarine, $\mathrm{H}$ : histamine, $5 \mathrm{HT}$ : serotonin (modified from [24-26]). 
Table 4. Receptor Affinities of Antipsychotics

\begin{tabular}{|c|c|c|c|c|c|c|c|c|c|c|c|}
\hline Receptor & Clozapine & Risperidone & Dlanzapine & Quetiapine & Ziprasidone & Sertindole & Sulpiride & Amisulpride & Zotepine & Aripiprazole & Haloperidol \\
\hline$D_{1}$ & + & + & ++ & - & + & ++ & - & - & + & - & + \\
\hline $\mathrm{D}_{2}$ & + & +++ & ++ & + & +++ & +++ & +++ & ++++ & ++ & ++++ & ++++ \\
\hline $\mathrm{D}_{3}$ & + & ++ & + & - & ++ & ++ & ++ & ++ & ++ & ++ & +++ \\
\hline $\mathrm{D}_{4}$ & ++ & - & ++ & - & ++ & + & - & - & + & + & +++ \\
\hline $5 \mathrm{HT}_{1 \mathrm{~A}}$ & - & - & - & - & +++ & & & & ++ & ++ & - \\
\hline $5 \mathrm{HT}_{1 \mathrm{D}}$ & - & + & - & - & +++ & & & & & + & - \\
\hline $5 \mathrm{HT}_{2 \mathrm{~A}}$ & +++ & +++ & +++ & ++ & +++ & ++++ & - & - & +++ & +++ & + \\
\hline $5 \mathrm{HT}_{2 \mathrm{C}}$ & ++ & ++ & ++ & - & +++ & ++ & - & - & ++ & + & - \\
\hline $5 \mathrm{HT}_{6}$ & ++ & - & ++ & - & + & & & & ++ & + & - \\
\hline $5 \mathrm{HT}_{7}$ & ++ & +++ & - & - & ++ & & & & ++ & ++ & - \\
\hline$\alpha_{1}$ & +++ & +++ & ++ & +++ & ++ & ++ & - & - & ++ & + & +++ \\
\hline$\alpha_{2}$ & + & ++ & + & - & - & + & - & - & ++ & + & - \\
\hline $\mathrm{H}_{1}$ & +++ & - & +++ & ++ & - & + & - & - & ++ & + & - \\
\hline$M_{1}$ & ++++ & - & +++ & ++ & - & - & - & - & + & - & - \\
\hline
\end{tabular}

$-:$ minimal to none, + : low, ++ : moderate, +++ : high, ++++ : very high (adapted and modified from [24,25]).

tion of the SGAs, compared to haloperidol (FGAs), are reduced $\mathrm{D}_{2}$ and increased $5-\mathrm{HT}_{2 \mathrm{~A}}$ receptor binding. Compared to haloperidol, clozapine, quetiapine, olanzapine, and zotepine show a lower affinity to the $\mathrm{D}_{2}$ receptor; however, risperidone, ziprasidone, sertindole, clozapine, olanzapine, zotepine, and aripiprazole have a higher affinity to the $5 \mathrm{HT}_{2 \mathrm{~A}}$ receptor.

\section{(2) Clinical applications, adverse reactions, and treat- ments of adverse reactions}

Long-term, the strong binding to the $\mathrm{D}_{2}$ receptor of FGAs produces two representative ADRs: EPSs and hyperprolactinemia. To avoid these ADRs, it is better to choose certain SGAs, such as clozapine, quetiapine, olanzapine, and zotepine, which produce short-term, weak binding to the receptor.

Regarding the $5 \mathrm{HT}_{2 \mathrm{~A}}$ receptor, which is related to sleep, certain SGAs, such as risperidone, ziprasidone, sertindole, clozapine, olanzapine, zotepine, aripiprazole, or quetiapine are preferred for the treatment of insomnia using the somnolescent effect of SGAs. On the contrary, sulpiride and amisulpride do not produce somnolence, like the FGA haloperidol (Table 4) [8,24-26].

Certain SGAs, such as, clozapine, olanzapine, quetiapine, and zotepine, which induce histamine $\mathrm{H}_{1}$ receptor blockade, may produce sedation and weight gain. On the contrary, risperidone, ziprasidone, sulpiride, and ami- sulpride, as well as haloperidol (FGA) do not produce sedation and weight gain (Table 4) [8,24-26].

Alpha-1 adrenergic antagonism by SGAs produces hypotension, sedation, and weight gain. Clozapine, risperidone, quetiapine, (haloperidol), ziprasidone, sertindole, and zotepine may produce these ADRs.

Focused on weight gain due to SGAs, clozapine, olanzapine, and quetiapine significantly increase the body mass index (BMI), however, risperidone, sertindole, zotepine, amisulpride, aripiprazole, and ziprasidone were less likely to increase BMI. Proposed mechanisms of weight gain by SGAs are related receptors (the $\mathrm{H}_{1}, 5-\mathrm{HT}_{2 \mathrm{~A}}$, $5-\mathrm{HT}_{2 \mathrm{C}}, \mathrm{M}_{3}$, and adrenergic receptors), reproductive hormones, other neurotransmitters, insulin, neuropeptides, cytokines, and genetic factors [27-30].

SGAs, such as olanzapine and clozapine, rather than quetiapine and ziprasidone, have been frequently reported as causing the development of new-onset diabetes mellitus (DM) and impaired glucose tolerance or exacerbation of existing type 1 and 2 DM. Supposed mechanisms include induction of peripheral insulin resistance and direct influence on pancreatic beta-cell function by $5-\mathrm{HT}_{1 \mathrm{~A} / 2 \mathrm{~A} / 2 \mathrm{C}} \mathrm{re}-$ ceptor antagonism, or inhibition of the alpha 2 adrenergic receptors. Known risk factors are a family history of DM, obesity, and Negroid ethnicity [31-33].

Anti-muscarinic effects due to $\mathrm{M}_{1}$ blockade, such as dry mouth, may exhibit themselves during the administration of clozapine, olanzapine, quetiapine, and zote- 
pine, in order of frequency. On the contrary, SGAs, such as risperidone, ziprasidone, sertindole, sulpiride, aripiprazole, as well as haloperidol (FGA), do not produce anticholinergic ADRs (Table 4) [8,24-26].

\section{Dose equivalent conversions}

The response to antipsychotics may differ from patient to patient. Antipsychotic equivalent oral doses are usually used based on $100 \mathrm{mg}$ of chlorpromazine (CPZ) daily, and the daily oral dose is similar to $2(1-5) \mathrm{mg}$ of haloperidol, 100 (30-150) $\mathrm{mg}$ of clozapine, and $2(0.5-3) \mathrm{mg}$ of risperidone. However, even though the equivalent dose of other second-generation antipsychotic (SGA) drugs are not precisely established, $75 \mathrm{mg} / \mathrm{d}$ of quetiapine, $5 \mathrm{mg} / \mathrm{d}$ of olanzapine, and $7.5 \mathrm{mg} / \mathrm{d}$ of aripiprazole are equivalent to $100 \mathrm{mg} / \mathrm{d}$ of $\mathrm{CPZ}$ [34-36].

For $1 \mathrm{mg} / \mathrm{d}$ of olanzapine, the equivalent doses of antipsychotics were as follows; CPZ $38.88 \mathrm{mg} / \mathrm{d}$, haloperidol $0.74 \mathrm{mg} / \mathrm{d}$, clozapine $30.62 \mathrm{mg} / \mathrm{d}$, quetiapine $32.27 \mathrm{mg} / \mathrm{d}$, amisulpride $38.33 \mathrm{mg} / \mathrm{d}$, aripiprazole $1.41 \mathrm{mg} / \mathrm{d}$, asenapine $0.89 \mathrm{mg} / \mathrm{d}$, risperidone $0.38 \mathrm{mg} / \mathrm{d}$, sertindole $1.08 \mathrm{mg} / \mathrm{d}$, ziprasidone $7.92 \mathrm{mg} / \mathrm{d}$, and zotepine $13.24 \mathrm{mg} / \mathrm{d}$ [37,38].

Although there would be potential for ADRs, the typical doses $(\mathrm{mg} / \mathrm{d})$ of each SGA are as follows; risperidone (3-6 $\mathrm{mg} / \mathrm{d})$, olanzapine and aripiprazole (10-20 mg/d), ziprasidone (80-160 mg/d), quetiapine (300-600 mg/d), and clozapine $(300-450 \mathrm{mg} / \mathrm{d})$ [34-38].

\section{CONCLUSIONS}

It is well-known that both components of pain, which are composed of emotional and sensory experience, should be treated simultaneously. Antipsychotics may be effective if patinets show the positive symptoms of psychosis, such as delusion, hallucination, disorganized thought and behavior, perception disturbance, and inappropriate emotion.

Traditionally, non-psychiatric pain physicians hesitate to use FGAs because of ADRs, such as EPSs. The FGAs show their action by tight and longstanding $\mathrm{D}_{2}$ receptor binding blockade, however, the SGAs act by quick releasing, weak binding to the $\mathrm{D}_{2}$ receptor block and $5-\mathrm{H}_{2 \mathrm{~A}}$ receptor blockade. It is very important to recognize the EPSs from the beginning of the treatment, and to be well-acquainted with the treatment of EPSs.

Treatments include 1-6 mg/d of benz (a) tropine for dystonia, anticholinergics or 100-400 mg/d of amantadine for pseudo-parkinsonism, 30-120 mg/d of propranolol for akathisia, and valbenazine (12.5-100 mg/d) for 6 weeks for tardive dyskinesia. The abnormal involuntary movement scale (AIMS) is helpful for early detection of drug-induced tardive dyskinesia. Therefore, SGAs are expected to be used without difficulty, even though the potential metabolic ADRs, such as weight gain or DM, exist.

When choosing an SGA, it is wise to make the selection after considering their representative adverse reactions: 1) for reducing sedation, aripiprazole, iloperidone, lurasidone, paliperidone, risperidone, ziprasidone, asenapine, olanzapine, clozapine, and quetiapine would be better choices, in that order. However, for insomnia, using the adverse reaction of sedation, following the reverse order, from quetiapine, becomes a better practice, 2) for patients who worry about weight gain, the preference would be aripiprazole, lurasidone, ziprasidone, asenapine, iloperidone, paliperidone, risperidone, quetiapine, clozapine, and olanzapine, in descending order, and 3) for patients showing EPSs, clozapine, iloperidone, quetiapine, aripiprazole, asenapine, lurasidone, olanzapine, ziprasidone, paliperidone, and risperidone, in descending order, are preferred.

A drug is usually used for treating certain symptom and/or signs of various diseases, disorders, and syndromes. Antipsychotics can use not only for the treatment of psychosis, but also for pain patients with positive symptoms of psychosis. Therefore, SGAs are worth using for pain patients with the positive symptoms, such as delusion, hallucination, disorganized thought and behavior, perception disturbance, and inappropriate emotion, during or after controlling all sensory components, while reducing worries about EPSs.

\section{ACKNOWLEDGEMENTS}

This study was supported by a 2-year (from 2017 to 2019) research grant from Pusan National University (SangWook Shin).

\section{REFERENCES}

1. Pain terms: a list with definitions and notes on usage. Recommended by the IASP Subcommittee on Taxonomy. Pain 1979; 6: 249.

2. Stroup TS, Alves WM, Hamer RM, Lieberman JA. Clinical trials 
for antipsychotic drugs: design conventions, dilemmas and innovations. Nat Rev Drug Discov 2006; 5: 133-46.

3. Targum SD. Treating psychotic symptoms in elderly patients. Prim Care Companion J Clin Psychiatry 2001; 3: 156-63.

4. Leo RJ, Regno PD. Atypical antipsychotic use in the treatment of psychosis in primary care. Prim Care Companion J Clin Psychiatry 2000; 2: 194-204.

5. Seidel S, Aigner M, Ossege M, Pernicka E, Wildner B, Sycha T. Antipsychotics for acute and chronic pain in adults. Cochrane Database Syst Rev 2008: CD004844.

6. Seidel S, Aigner M, Ossege M, Pernicka E, Wildner B, Sycha T. Antipsychotics for acute and chronic pain in adults. J Pain Symptom Manage 2010; 39: 768-78.

7. Ramachandraiah CT, Subramaniam N, Tancer M. The story of antipsychotics: past and present. Indian J Psychiatry 2009; 51: 324-6.

8. Worrel JA, Marken PA, Beckman SE, Ruehter VL. Atypical antipsychotic agents: a critical review. Am J Health Syst Pharm 2000; 57: 238-55.

9. Gottries CG, Green L. Flupenthixol decanoate--in treatment of out-patients. Acta Psychiatr Scand Suppl 1974; 255: $15-24$.

10. Kapur S, Mamo D. Half a century of antipsychotics and still a central role for dopamine D2 receptors. Prog Neuropsychopharmacol Biol Psychiatry 2003; 27: 1081-90.

11. Howes OD, Kapur S. The dopamine hypothesis of Schizophrenia: version III--the final common pathway. Schizophr Bull 2009; 35: 549-62.

12. Yang AC, Tsai SJ. New targets for schizophrenia treatment beyond the dopamine hypothesis. Int J Mol Sci 2017; 18: 1689.

13. Inada T. Evaluation and diagnosis of drug-induced extrapyramidal symptoms: commentary on the DIEPSS and guide to its usage. Tokyo, Seiwa Shoten Publishers. 1996.

14. Knol W, Keijsers CJ, Jansen PA, van Marum RJ. Systematic evaluation of rating scales for drug-induced parkinsonism and recommendations for future research. J Clin Psychopharmacol 2010; 30: 57-63.

15. Chouinard G. Margolese HC. Manual for the Extrapyramidal Symptom Rating Scale (ESRS). Schizophr Res 2005; 76 : 247-65.

16. Holloman LC, Marder SR. Management of acute extrapyramidal effects induced by antipsychotic drugs. Am J Health Syst Pharm 1997; 54: 2461-77.

17. Albanese A, Bhatia K, Bressman SB, Delong MR, Fahn S, Fung VS, et al. Phenomenology and classification of dystonia: a consensus update. Mov Disord 2013; 28: 86373.

18. Skogseid M. Dystonia--new advances in classification, genetics, pathophysiology and treatment. Acta Neurol Scand 2014; 129: 13-9.

19. Kurlan R, Rabin ML. Pseudoparkinsonism: a review of a common nonparkinsonian hypokinetic movement disorder. Adv Parkinson Dis 2013; 2: 108-12.

20. Glazer WM, Morgenstern H, Doucette JT. Predicting the long-term risk of tardive dyskinesia in outpatients maintained on neuroleptic medications. J Clin Psychiatry 1993; 54: 133-9.

21. Munetz MR, Schulz SC. Screening for tardive dyskinesia. J Clin Psychiatry 1986; 47: 75-7.

22. Uhlyar S, Rey JA. Valbenazine (Ingrezza): the first FDAapproved treatment for tardive dyskinesia. P T 2018; 43: 328-31.

23. Markowitz JD, Narasimhan M. Delirium and antipsychotics: a systematic review of epidemiology and somatic treatment options. Psychiatry (Edgmont) 2008; 5: 29-36.

24. Seeman P. Atypical antipsychotics: mechanism of action. Can J Psychiatry 2002; 47: 27-38.

25. Glazer WM. Extrapyramidal side effects, tardive dyskinesia, and the concept of atypicality. J Clin Psychiatry 2000; 61: $16-21$.

26. Miller DD. Atypical antipsychotics: sleep, sedation, and efficacy. Prim Care Companion J Clin Psychiatry 2004; 6: 3-7.

27. Brixner DI, Said Q, Corey-Lisle PK, Tuomari AV, L'italien GJ, Stockdale W, et al. Naturalistic impact of second-generation antipsychotics on weight gain. Ann Pharmacother 2006; 40: 626-32.

28. Gentile S. Contributing factors to weight gain during longterm treatment with second-generation antipsychotics. A systematic appraisal and clinical implications. Obes Rev 2009; 10: 527-42.

29. Roerig JL, Steffen KJ, Mitchell JE. Atypical antipsychoticinduced weight gain: insights into mechanisms of action. CNS Drugs 2011; 25: 1035-59.

30. Taylor DM, McAskill R. Atypical antipsychotics and weight gain--a systematic review. Acta Psychiatr Scand 2000; 101: 416-32.

31. Cohen D. Atypical antipsychotics and new onset diabetes mellitus. An overview of the literature. Pharmacopsychiatry 2004; 37: 1-11.

32. Schwenkreis P. Assion HJ. Atypical antipsychotics and diabetes mellitus. World J Biol Psychiatry 2004; 5: 73-82.

33. Haupt DW, Newcomer JW. Hyperglycemia and antipsychotic medications. J Clin Psychiatry 2001; 62: 15-26.

34. Leucht S, Samara M, Heres S, Patel MX, Woods SW, Davis JM. Dose equivalents for second-generation antipsychotics: the minimum effective dose method. Schizophr Bull 2014; 40: 314-26.

35. Leucht S, Samara M, Heres S, Patel MX, Furukawa T, Cipriani $A$, et al. Dose equivalents for second-generation antipsychotic drugs: the classical mean dose method. Schizophr Bull 2015; 41: 1397-402.

36. Woods SW. Chlorpromazine equivalent doses for the newer 
Shin, et al / Antipsychotics for patients with pain || 11

atypical antipsychotics. J Clin Psychiatry 2003; 64: 663-7.

37. Khouzam HR. Psychopharmacology of chronic pain: a focus on antidepressants and atypical antipsychotics. Postgrad Med 2016; 128: 323-30.
38. Gardner DM, Baldessarini RJ, Waraich P. Modern antipsychotic drugs: a critical overview. CMAJ 2005; 172: 1703-11. 